\title{
Examination of protective and therapeutic effects of ruscogenin on cerulein-induced experimental acute pancreatitis in rats
}

\author{
Gulcin Ercan¹, Rumeysa İlbar Tartar², Ali Solmaz¹, Osman Bilgin Gulcicek¹, Onur Olgac Karagulle², \\ Serhat Meric ${ }^{1}$, Huseyin Cayoren ${ }^{4}$, Ramazan Kusaslan ${ }^{5}$, Ahu Kemik ${ }^{6}$, Damla Gokceoglu Kayali ${ }^{7}$, Sule Cetinel ${ }^{7}$, \\ Atilla Celik ${ }^{1}$ \\ ${ }^{1}$ Department of General Surgery, University of Health Sciences Bagcilar Training and Research Hospital, Istanbul, Turkey \\ ${ }^{2}$ Department of General Surgery, Sisli Hamidiye Etfal Training and Research Hospital, University of Health Sciences, Istanbul, \\ Turkey \\ ${ }^{3}$ Department of General Surgery, Buyukcekmece Mimar Sinan State Hospital, Istanbul, Turkey \\ ${ }^{4}$ Department of General Surgery, Igdir State Hospital, Igdir, Turkey \\ ${ }^{5}$ Department of General Surgery, Elitium Surgery Center, Istanbul, Turkey \\ ${ }^{6}$ Department of Biochemistry, Cerrahpasa School of Medicine, Istanbul University, Istanbul, Turkey \\ ${ }^{7}$ Department of Histology and Embryology, School of Medicine, Marmara University, Istanbul, Turkey
}

\begin{abstract}
Purpose: To determine the potential protective and therapeutic effects and action mechanism of ruscogenin on ceruleininduced acute pancreatitis (AP) model in rats.

Methods: Overall, 32 rats were attenuated to the sham (2- $\mathrm{mL} / \mathrm{kg} /$ day isotonic solution for 4 weeks), control $(20-\mu \mathrm{g} / \mathrm{kg}$ cerulein-induced AP for 12 hours), prophylaxis groups (cerulein-induced AP following 3-mL/kg/day ruscogenin for 4 weeks) and treatment (3- $\mathrm{mL} / \mathrm{kg} /$ day ruscogenin following cerulein-induced AP for 12 hours). Blood samples were collected for biochemical analysis of nitric oxide synthase 1 (NOS1/neuronal NOS), malondialdehyde (MDA) and intercellular adhesion molecule 1 (ICAM-1). After sacrification, pancreas tissues were collected and prepared for light microscopic (hematoxylin and eosin), immunohistochemical (nuclear factor kappa B) and biochemical analysis (tumor necrosis factor-alpha [TNF- $\alpha$ ], interleukin- 6 and $1 \beta$ [IL- 6 and IL-1 $\beta$ ], CRP, high-sensitivity CRP [hs-CRP] amylase, lipase, and ICAM-1). Ultrastructural analysis was performed by transmission electron microscopy.

Results: The protective and therapeutic actions of ruscogenin were accomplished by improvements in histopathology, by decreasing blood cytokine levels of CRP, hs-CRP levels, TNF- $\alpha$, IL-6, IL-1 $\beta$, ICAM-1, by reducing the pancreatic enzymes amylase and lipase in blood, and by suppressing the expression of nuclear factor kappa B, ICAM-1, and NOS-1, but not MDA in pancreatic tissues. Ruscogenin also improved cerulein-induced ultrastructural degenerations in endocrine and exocrine cells, especially in treatment group.

Conclusion: The present findings have demonstrated the beneficial protective and therapeutical effects of ruscogenin, nominating it as a highly promising supplementary agent to be considered in the treatment of AP, and even as a protective agent against the damages induced by disease.

[Ann Surg Treat Res 2019;97(6):271-281]
\end{abstract}

Key Words: Ceruletide, NF-kappa B, Pancreas, Pancreatitis, Ruscogenin

Received September 4, 2019, Revised October 11, 2019,

Accepted October 23, 2019

Corresponding Author: Gulcin Ercan

Department of General Surgery, University of Health Sciences Bagcilar, Training and Research Hospital, Street of Dr. Sadik Ahmet, Bagcilar, 34200 Istanbul, Turkey

Tel: +90-530-551-6212, Fax: +90-212-440-4242

E-mail: ghepgul@hotmail.com

ORCID: https://orcid.org/0000-0001-8420-9298
Copyright (C) 2019, the Korean Surgical Society

(C) Annals of Surgical Treatment and Research is an Open Access Journal. All articles are distributed under the terms of the Creative Commons Attribution NonCommercial License (http://creativecommons.org/licenses/by-nc/4.0/) which permits unrestricted non-commercial use, distribution, and reproduction in any medium, provided the original work is properly cited. 


\section{INTRODUCTION}

Acute pancreatitis (AP) is a common and potentially lethal acute inflammatory disease associated with the release of digestive enzymes to the pancreatic interstitium and to systemic circulation, resulting in elevated production and release of cytokines, and ultimately in destructive local and systemic effects [1]. Systemic manifestations of the AP are mediated by a variety of pro- and anti-inflammatory mediators released from the pancreas and various other sources during the course of the disease. Local recruitment and activation of inflammatory cells in AP lead to the production of proinflammatory cytokines, such as interleukins (IL)-6, IL-8, and tumor necrosis factoralpha (TNF- $\alpha$ ), which are mostly studied as markers of severity of AP [2]. Activated pancreatic macrophages release TNF- $\alpha$ in response to local tissue damage, acting locally to aggravate $\mathrm{AP}$ and systemically with IL-6 to increase capillary permeability and promote leukocyte adherence and extravasation, leading to multiple organ failure [3]. Another commonly examined marker for AP is CRP [4].

Oxidative stress is known as the major pathogenic factor in the AP [5]. Cerulein, a cholecystokinin (CCK) analogue (pGluGln-[Met3]-CCK8, sulphated), produces large amounts of reactive oxygen species (ROS) which are important mediators in the initiation and development of pancreatitis. ROS activate the oxidant-sensitive nuclear transcription factor (nuclear factor kappa B, NF- $\mathrm{B}$ ) and thus induce cytokine expression in the pancreatic acinar cells [6]. Among several animal models of experimental pancreatitis that exhibit the biochemical, histomorphological, and pathophysiological similarities to various aspects of human pancreatitis, cerulein pancreatitis was shown to be one of the best-characterized and widely used experimental models [7]. Different doses of cerulein causes variations in the pancreatic secretion of amylase and lipase resulting in pancreatitis [1], which is characterized by a dysregulation of the production and secretion of digestive enzymes, particularly, the inhibition of pancreatic secretion and an elevation in their serum levels, cytoplasmic vacuolization and the death of acinar cells, interstitial edema, and an infiltration of inflammatory cells into the pancreas [8].

Severe AP is associated with high morbidity and mortality due to the development of pancreatic and extrapancreatic necrosis, their subsequent infection and multisystem organ failure [9]. Based on the pathophysiology of AP and the basic science research conducted providing evidence for promising pharmacologic therapy, many clinical studies have been performed assessing the effectiveness of these therapies including anti-secretory agents, protease inhibitors, immunomodulators, anti-inflammatory agents, and antioxidants [10,11]. Different anti-inflammatory agents and antioxidants such as ROS scavengers targeting the production of superoxide in the activated neutrophils, the expressions of the inflammatory cytokines, or the NF- $\mathrm{KB}$ activation, have been investigated in the treatment of AP [12]. However, there is still need to find the underlying mechanism of the disease that may serve as the potential therapeutic target in the development of new drugs, which may serve as a minimally invasive approach in the management of AP.

Ruscogenin ( $[1 \beta, 3 \beta, 25 \mathrm{R}]$-Spirost-5-ene-1,3-diol), a main steroid sapogenin of a traditional Chinese plant called 'Ophiopogon japonicus,' was first isolated from 'Ruscus aculeatus' and has been found to have notable anti-inflammatory and antithrombotic activities [13]. Previous studies have revealed that the potent anti-inflammatory mechanism of ruscogenin is essentially related to the inhibition of nuclear factor kappa $B$ (NF-KB) signal pathways and of the expression of intercellular adhesion molecule-1 (ICAM-1) [13]. However, there are no reports about the therapeutic effects of ruscogenin on AP, and the underlying mechanisms remain unclear. Thus, we aimed to evaluate the possible therapeutic effects of ruscogenin on the cerulein-induced AP by using macroscopic, histopathological, immunohistochemical, biochemical, and electron microscopic methods.

\section{METHODS}

\section{Animals}

All experimental procedures of this study were approved by the Research Ethics Committee of The Bagcilar Training and Research Hospital of Health Science University approved (protocol number: 2016/24, date of approval: 12 August 2016).

Thirty-two female Sprague-Dawley rats (250 $\pm 30 \mathrm{~g}$ ), supplied by the Bagcilar Training and Research Hospital Animal Center (BADABEM), Istanbul, Turkey, were kept under laboratory conditions of the same center, housed in a controlled room with 12hour light-dark cycles at $22^{\circ} \mathrm{C}$, and fed with standard pellet chow including 21\% protein and daily fresh water. Exclusion criteria were a weight loss of more than $20 \%$, irregular nourishment and less drinking water, and a significant decrease in response to stimuli during the experiments.

All rats were separated in cages of 8 rats each and were divided into 4 random groups $(n=8)$ as follows;

Group 1. Sham group received $2 \mathrm{~mL} / \mathrm{kg} / \mathrm{day}$ amount of isotonic solution (IS) by gavage for 4 weeks

Group 2. Control (AP) group was injected with a $20-\mu \mathrm{g} / \mathrm{kg}$ dose of cerulein 4 times at 1-hour intervals intraperitoneally

Group 3. Prophylaxis group received a 3-mg/kg/day dose of ruscogenin (H10000934, Abdi İbrahim Drug Industry and Trade Inc., Istanbul, Turkey) daily for 4 weeks by gavage, following 4 intraperitoneal injections of $20-\mu \mathrm{g} / \mathrm{kg}$ cerulein at 1 -hour intervals

Group 4. Treatment group received a $20-\mu \mathrm{g} / \mathrm{kg}$ dose of ce- 
rulein 4 times at 1-hour intervals, simultaneously with a 3-mg/ $\mathrm{kg} /$ day dose of ruscogenin applied by gavage.

\section{Induction of AP}

AP was induced by intraperitoneal administration of $20 \mu \mathrm{g} /$ $\mathrm{kg}$ of cerulein 4 times at 1-hour intervals. Twelve hours after the last dose of cerulein, the rats were sacrificed by cardiac puncture under 80-mg/kg ketamine (Ketalar, Pfizer, Turkey) and 5-mg/kg xylazine (Rompun, Bayer, Turkey) anesthesia, and approximately 4- to 5-mL blood samples were collected during intracardiac puncture.

There were no anesthetic complications or death which may conduce to exclude any rat from the experimental procedures. There were no side effects like inflammation on wounds or vomiting due to oral medication.

\section{Morphological analysis}

After sacrificing the rats, the pancreatic tissue obtained was washed rapidly with saline and fixed for 72 hours in $10 \%$ neutral buffered formalin for light microscopic examination. Tissues were then dehydrated by passing through a rising alcohol series $(70 \%, 90 \%, 96 \%, 100 \%)$, cleared by keeping in xylene for $2 \times 10$ minutes. Hematoxylin and eosin staining was applied to the sections obtained from paraffin blocks with a thickness of approximately $4 \mu \mathrm{m}$. All stained sections were evaluated on a light microscope (Olympus BX51, Olympus, Tokyo, Japan) with the camera attachment (Olympus DP72, Olympus) by 2 experienced histologists, who were unaware of the experimental groups. Pancreatic injury was evaluated (Table
1) based on an adapted version of a semiquantitative evaluation [14]. The hypertrophy, autophagy and necrosis of acinar cells, vascular damage, interstitial edema, and ductal variation were given a histopathological score as 0 , none; 1 , mild; 2 , moderate; 3, severe.

\section{Immunohistochemical analysis}

In accordance with a previously described method [15], the paraffin sections were stained immunohistochemically by using streptavidin-biotin-peroxidase method with monoclonal and polyclonal antibody tagged to indicate NF- $\mathrm{B}$ (anti-NFкB p65 antibody, SAB4502610, Merck, Darmstadt, Germany). Biotinylated secondary antibodies and streptavidin-biotinperoxidase conjugates, 3,3'-Diaminobenzidine were purchased from Invitrogen (HistostainPlus Kit, Life Technologies, Carlsbad, CA, USA). Counter staining was performed by Mayer Hematoxylin and positively staining with relevant antigens were analyzed semiquantitatively in terms of staining intensity ( 0 , no staining; 1 , weak reactivity; 2 , moderate reactivity; 3 , strong reactivity) [16].

\section{Biochemical analysis}

Blood and pancreatic tissue samples were collected for biochemical analysis. Blood cytokine levels of IL1 $\beta$, IL-6, TNF- $\alpha$, CRP, high-sensitivity CRP (hs-CRP) and the biochemical parameters (amylase, lipase) and ICAM-1 were examined by enzyme-linked immunosorbent assay (ELISA). The tissue amounts of antioxidant system-related parameters, nitric oxide (NO) and malondialdehyde (MDA) and ICAM-1 were

Table 1. Semiquantitative histopathological scores of pancreatic damage

\begin{tabular}{|c|c|c|c|c|}
\hline \multirow{2}{*}{$\begin{array}{l}\text { Feature of } \\
\text { pancreatic } \\
\text { damage }\end{array}$} & \multicolumn{4}{|c|}{ Score } \\
\hline & 0 & 1 & 2 & 3 \\
\hline $\begin{array}{l}\text { Acinar cell } \\
\text { hypertrophy }\end{array}$ & No hypertrophy & $\begin{array}{l}\text { Rare hypertrophy in individual } \\
\text { acinar cells }\end{array}$ & Nodular hypertrophy & $\begin{array}{l}\text { Hypertrophy in most of acinar } \\
\text { cells in the lobules }\end{array}$ \\
\hline $\begin{array}{l}\text { Acinar cell } \\
\text { autophagy }\end{array}$ & No autophagy & Small cytoplasmic vesicles & $\begin{array}{l}\text { A little number of cells with } \\
\text { middle/large cytoplasmic } \\
\text { vacuoles }\end{array}$ & $\begin{array}{l}\text { Large single/combined cell } \\
\text { clusters with vacuoles }\end{array}$ \\
\hline $\begin{array}{l}\text { Acinar cell } \\
\text { necrosis }\end{array}$ & No necrotic cell & Necrotic individual acinar cell & $\begin{array}{l}\text { Necrotic cell debris frequently } \\
\text { with neutrophils and } \\
\text { bleeding }\end{array}$ & $\begin{array}{l}\text { Necrotic lobules, frequently } \\
\text { inflammatory cell clusters with } \\
\text { bleeding }\end{array}$ \\
\hline $\begin{array}{r}\text { Vascular } \\
\text { damage }\end{array}$ & $\begin{array}{l}\text { No vascular } \\
\text { damage }\end{array}$ & $\begin{array}{l}\text { Capillary dilatation and } \\
\text { migration of neutrophils to } \\
\text { perivascular spaces surrounding } \\
\text { small vessels }\end{array}$ & $\begin{array}{l}\text { Arterial fibronoid necrosis, } \\
\text { fibrin exudation, perivascular } \\
\text { inflammation }\end{array}$ & $\begin{array}{l}\text { Fibroid necrosis of medium- } \\
\text { sized arteries, hemorrhage, } \\
\text { and inflammatory cell } \\
\text { infiltration }\end{array}$ \\
\hline $\begin{array}{l}\text { Interstitial } \\
\text { edema }\end{array}$ & $\begin{array}{l}\text { No interstitial } \\
\text { edema }\end{array}$ & $\begin{array}{l}\text { Mild interlobular edema, no } \\
\text { inflammation and no } \\
\text { hemorrhage }\end{array}$ & $\begin{array}{l}\text { Moderate intralobular edema, } \\
\text { inflammation, and } \\
\text { hemorrhage }\end{array}$ & $\begin{array}{l}\text { Severe intercellular edema, } \\
\text { inflammation, and hemorrhage }\end{array}$ \\
\hline $\begin{array}{l}\text { Ductal } \\
\text { variation }\end{array}$ & $\begin{array}{l}\text { No ductal } \\
\text { variation }\end{array}$ & $\begin{array}{l}\text { Mild centroacinar cell } \\
\text { proliferation, hyperplasia of } \\
\text { intercalated ducts, inflammation } \\
\text { in intralobular ducts and } \\
\text { interacinar fibrosis }\end{array}$ & $\begin{array}{l}\text { Ductal dilatation and } \\
\text { periductal inflammation of } \\
\text { intralobular ducts and } \\
\text { intralobular fibrosis }\end{array}$ & $\begin{array}{l}\text { Ductal dilatation, epithelial cell } \\
\text { proliferation, periductal } \\
\text { inflammation of interductal } \\
\text { channels, and lobular fibrosis }\end{array}$ \\
\hline
\end{tabular}


also analyzed. Blood samples were allowed to clot at room temperature, centrifuged for 15 minutes at $1,000 \times \mathrm{g}$. The supernatants were collected. Pancreatic tissues were minced to small pieces and rinsed in ice-cold phosphate buffered saline to remove excess blood thoroughly. Tissue pieces were homogenized for 8 minutes at 20,000 rpm in $100 \mu \mathrm{L} 0.02 \mathrm{M}$ ethylenediaminetetraacetic acid. Homogenates were centrifuged for 5 minutes at 5,000 $\times \mathrm{g}$ and supernatants were collected.

ELISA methods were applied according to the manufacturer's instructions without any modifications by using rat SICAM/ CD54 ELISA Kit (E-EL-R0369, Elabscience, Houston, TX, USA), CRP ELISA Kit (E-EL-R0022, Elabscience), hs-CRP ELISA kit (E-EL-R0506, Elabscience), IL-6 ELISA Kit (E-EL-R0015, Elabscience), IL-1 $\beta$ ELISA kit (E-EL-R05012, Elabscience), MDA ELISA kit (E-EL-0060, Elabscience), NOS1/nNOS ELISA kit (E-EL-R1438, Elabscience), TNF- $\alpha$ ELISA kit (E-EL-R0019, Elabscience), Amylase Alpha 1 (AMY1) ELISA kit (E-EL-R2544, Elabscience), endothelial lipase ELISA kit (E-EL-0365, Elabscience). Optical densities were read on a plate reader set at $450 \pm$ $2 \mathrm{~nm}$. The concentration of each parameter in the samples was calculated from the standard curve, multiplied by the dilution factor and was expressed as mean \pm standard error of the mean (SEM).

\section{Statistical methods}

All data are expressed as means \pm SEM with all rats per group. Instat statistical package (GraphPad Software, San Diego, CA, USA) was used. Following the assurance of normal distribution of data, 1-way analysis of variance with the Tukey-
Kramer post hoc test was used for multiple comparison. Values of $\mathrm{P}<0.05, \mathrm{P}<0.01$ and $\mathrm{P}<0.001$ were regarded as significant.

\section{RESULTS}

\section{Histopathological findings}

The sham group had a normal structure of exocrine pancreas including cells with normal basal nuclei and apical acidophilic cytoplasm, as well as a regular islet morphology in endocrine pancrease (Fig. 1A), whereas the cerulein-induced pancreatitis group (control group) had increased acinar cell hypertrophy, autophagy, necrosis, and vascular damage, interstitial edema, and ductal variation (Fig. 1B). The histopathological changes in the control group were statistically significant $(P<0.05)$ (Table 2). In addition, dilated interlobular spaces and scattered islet cells were found in the control group (Fig. 1B). On the other hand, the pancreatic tissues in prophylaxis and treatment group had a significant decrease in the hypertrophy, autophagy, necrosis of acinar cells, and vascular damage, interstitial edema, and ductal variation compared with the control group (Table 2). Moreover, the general appearance of Langerhans islets in both ruscogenin groups was observed as normal as in the sham group (Fig. 1C, D). There was no significant difference between the histopathologies of prophylaxis and treatment groups, as well as sham group.

\section{Immunohistochemical findings}

The number of NF- $\mathrm{kB}$ positive cells in the pancreatic tissues
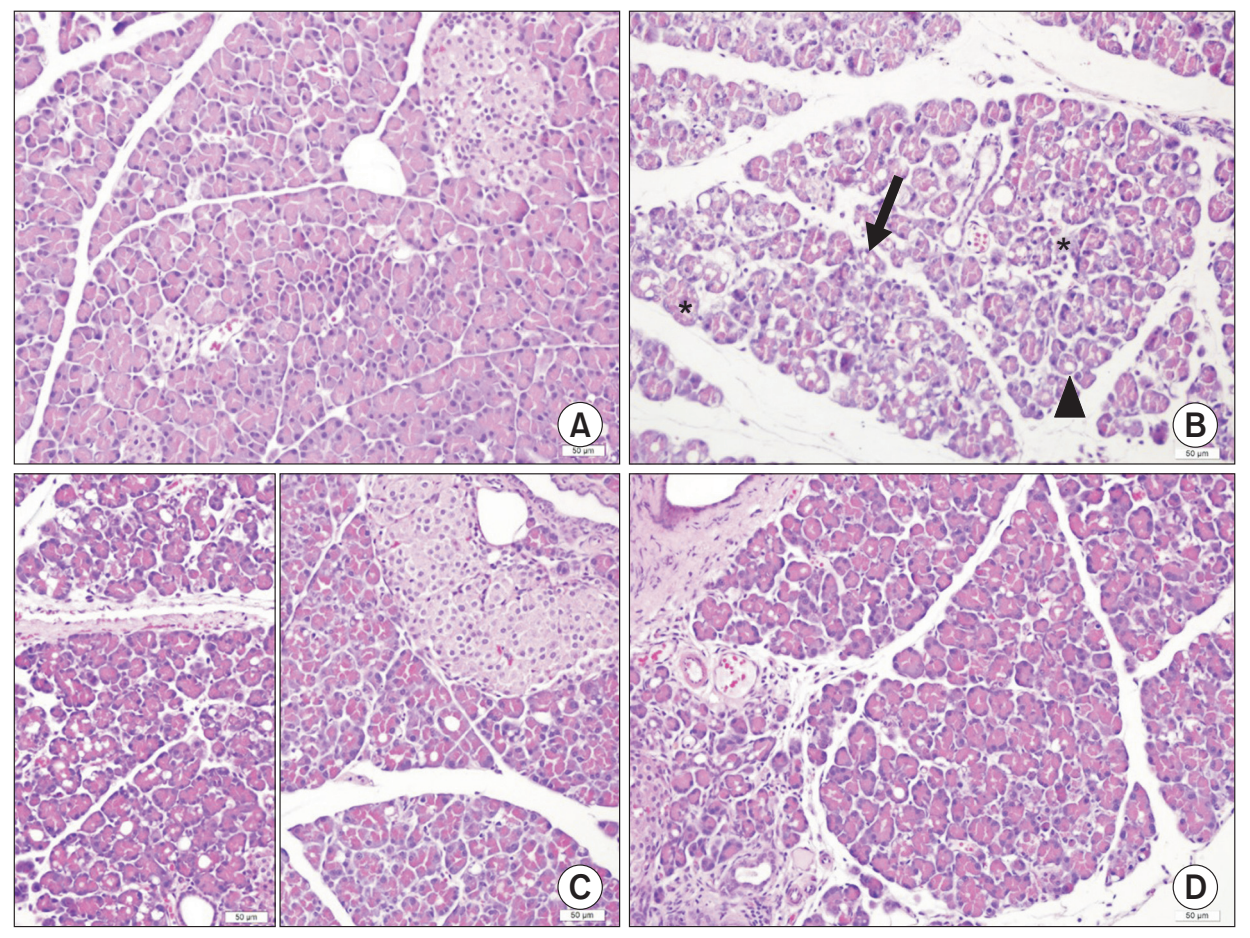

Fig. 1. Pancreatic tissues of experimental acute pancreatitis. (A) Sham group. (B) Control group. (C) Prophylaxis group. (D) Treatment group. Arrowhead: cytoplasmic vacuole, Asterisk: necrosis, Arrow: damage in the unity of acinar cells. H\&E stain. Scale bar represents $50 \mu \mathrm{m}$. 
Table 2. Histopathological scores of pancreatic tissues of the acute pancreatitis rats

\begin{tabular}{lcccccc}
\hline \multicolumn{1}{c}{ Group } & $\begin{array}{c}\text { Acinar cell } \\
\text { hypertrophy }\end{array}$ & $\begin{array}{c}\text { Acinar cell } \\
\text { autophagy }\end{array}$ & $\begin{array}{c}\text { Acinar cell } \\
\text { necrosis }\end{array}$ & Vascular damage & Interstitial edema & Ductal variation \\
Sham & $0.20 \pm 0.12$ & $0.0 \pm 0.0$ & $0.0 \pm 0.0$ & $0.0 \pm 0.0$ & $0.10 \pm 0.10$ & $0.0 \pm 0.0$ \\
Control & $2.30 \pm 0.20^{\mathrm{a})}$ & $2.20 \pm 0.20^{\mathrm{a})}$ & $1.9 \pm 0.10^{\mathrm{a})}$ & $2.20 \pm 0.20^{\mathrm{a})}$ & $2.40 \pm 0.25^{\mathrm{a})}$ & $1.60 \pm 0.25^{\mathrm{a})}$ \\
Prophylaxis & $0.80 \pm 0.12^{\mathrm{b})}$ & $0.80 \pm 0.12^{\mathrm{b})}$ & $0.80 \pm 0.12^{\mathrm{b})}$ & $1.20 \pm 0.20^{\mathrm{c})}$ & $1.40 \pm 0.24^{\mathrm{c})}$ & $0.80 \pm 0.12^{\mathrm{b})}$ \\
Treatment & $\left.1.00 \pm 0.16^{\mathrm{c}}\right)$ & $0.90 \pm 0.10^{\mathrm{b})}$ & $0.70 \pm 0.12^{\mathrm{b})}$ & $0.90 \pm 0.10^{\mathrm{b})}$ & $1.20 \pm 0.20^{(\mathrm{c})}$ & $0.70 \pm 0.20^{\mathrm{b})}$ \\
P-value & 0.001 & $<0.001$ & $<0.001$ & $<0.001$ & $<0.001$ & 0.003 \\
\hline
\end{tabular}

Values are presented as mean \pm standard error of the mean.

Kruskal-Wallis test (nonparametric analysis of variance) and Dunn multiple comparisons test.

${ }^{a)} \mathrm{P}<0.001$ vs. sham group. ${ }^{\text {b) }} \mathrm{P}<0.01,{ }^{\mathrm{c}} \mathrm{P}<0.05$ vs. control group.

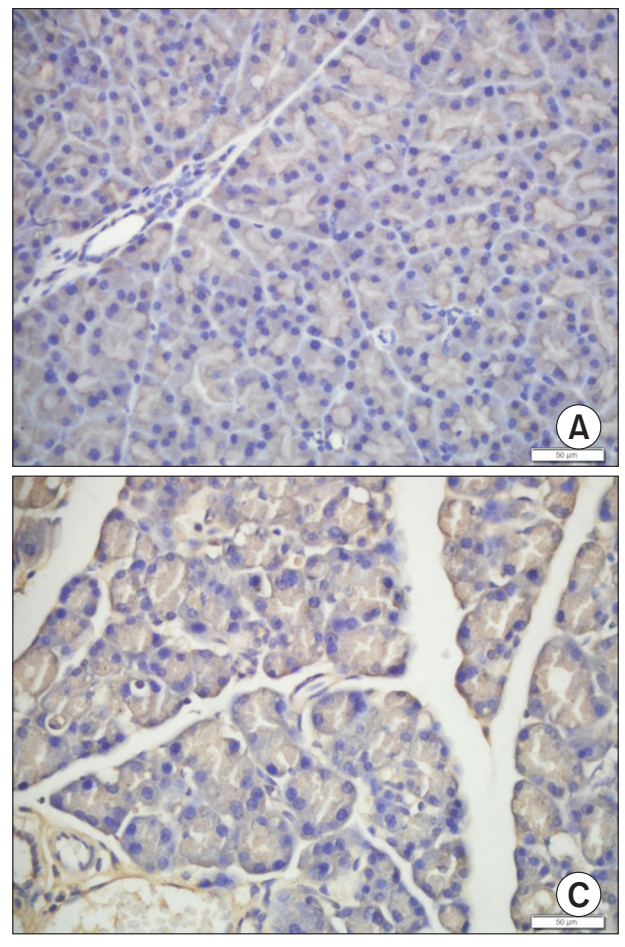

was very low in the sham group (Fig. 2A) while the number was highest in the cerulein-induced pancreatitis group, especially in the periacinar, perivascular, and periductal regions (Fig. 2B). The immunohistochemical scores showed a considerable increase in immunoreactivites of NF- $\mathrm{KB}$ in the control group compared with other groups (Fig. 3). On the other hand, pretreatment and posttreatment with ruscogenin led to a dramatic decrease in the number of positive cells (Fig. 2C); in fact, there were rare positive cells in the perivascular region of pancreases in the treatment group (Fig. 2D). The immunoreactivity scores for NF- $\mathrm{KB}$ were decreased to the normal levels both in the prophylaxis and treatment groups compared with the control group $(\mathrm{P}<0.001)$ but there was no statistical difference between prophylaxis and treatment groups (Fig. 3).

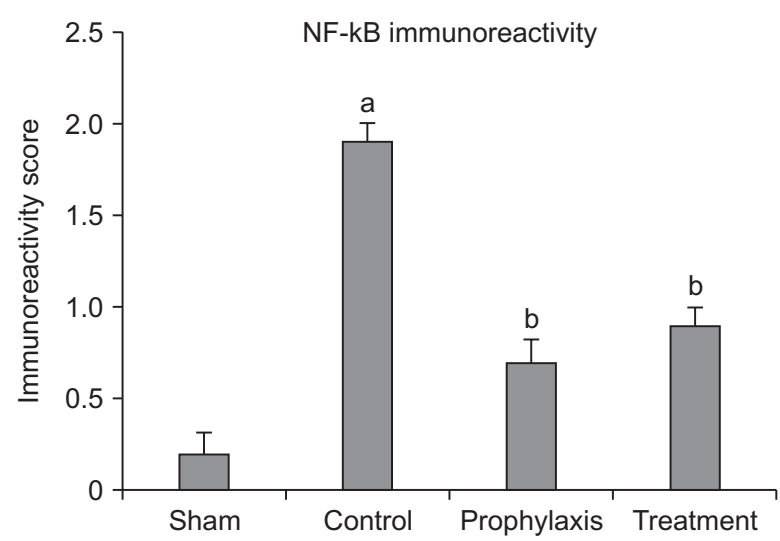

Fig. 3. Immunohistochemical scores of nuclear factor kappa $\mathrm{B}(\mathrm{NF}-\kappa \mathrm{B})$ in pancreatic tissues of acute pancreatitis rats. Values are presented as mean \pm standard error of the mean. ${ }^{a)} \mathrm{P}<0.001$ vs. sham group, ${ }^{\text {b) }} \mathrm{P}<0.001$ vs. control group, Kruskal-Wallis test (nonparametric analysis of variance) and Dunn multiple comparisons test. 
Table 3. Biochemical findings of blood samples from the acute pancreatitis rats

\begin{tabular}{|c|c|c|c|c|c|}
\hline Group & Sham & Control & Prophylaxis & Treatment & P-value \\
\hline CRP & $2.55 \pm 0.12$ & $3.44 \pm 0.11^{\mathrm{a})}$ & $2.55 \pm 0.10^{c)}$ & $2.55 \pm 0.12^{\mathrm{c})}$ & $<0.001$ \\
\hline hs-CRP & $2.85 \pm 0.05$ & $4.53 \pm 0.08^{\mathrm{a})}$ & $4.11 \pm 0.07^{\mathrm{a}, \mathrm{d})}$ & $3.88 \pm 0.13^{\mathrm{a}, \mathrm{c} c}$ & $<0.001$ \\
\hline ICAM-1 & $1.78 \pm 0.06$ & $5.24 \pm 0.17^{\mathrm{a})}$ & $4.26 \pm 0.14^{\mathrm{a}, \mathrm{c} c}$ & $2.49 \pm 0.13^{b, c)}$ & $<0.001$ \\
\hline IL-6 & $746.3 \pm 27.2$ & $1,218.8 \pm 40.0^{\mathrm{a})}$ & $915.9 \pm 10.1^{\mathrm{a}, \mathrm{c}}$ & $938.9 \pm 15.4^{a, c}$ & $<0.001$ \\
\hline IL-1 $\beta$ & $82.86 \pm 1.40$ & $121.33 \pm 1.51^{\text {a) }}$ & $91.74 \pm 1.41^{\mathrm{a}, \mathrm{c})}$ & $94.20 \pm 1.36^{\mathrm{a}, \mathrm{c}}$ & $<0.001$ \\
\hline TNF- $\alpha$ & $454.8 \pm 12.0$ & $775.2 \pm 18.2^{\mathrm{a})}$ & $632.9 \pm 31.9^{\mathrm{a}, \mathrm{e}}$ & $632.3 \pm 29.3^{\mathrm{a}, \mathrm{e})}$ & $<0.001$ \\
\hline Amylase & $24.01 \pm 1.72$ & $61.84 \pm 2.18^{\mathrm{a})}$ & $27.75 \pm 1.43$ & $30.59 \pm 0.82^{f)}$ & $<0.001$ \\
\hline Lipase & $27.43 \pm 0.77$ & $55.96 \pm 1.75^{\mathrm{a})}$ & $35.58 \pm 1.21^{\mathrm{a}, \mathrm{c}}$ & $39.99 \pm 0.54^{a, c}$ & $<0.001$ \\
\hline
\end{tabular}

Values are presented as mean \pm standard error of the mean.

Analysis of variance + Tukey-Kramer multiple comparisons test.

hs-CRP, high-sensitivity CRP; IL, interleukin; TNF, tumor necrosis factor.

${ }^{\text {a) }} \mathrm{P}<0.001,{ }^{\text {b) }} \mathrm{P}<0.01,{ }^{\text {ff }} \mathrm{P}<0.05$ vs. sham group. ${ }^{\text {c) }} \mathrm{P}<0.001$, ${ }^{\text {d) }} \mathrm{P}<0.05$, ${ }^{\text {e) }} \mathrm{P}<0.01$ vs. control group.

Table 4. Biochemical findings of pancreatic tissues from the acute pancreatitis rats

\begin{tabular}{lrrrrr}
\hline \multicolumn{1}{c}{ Group } & \multicolumn{1}{c}{ Sham } & \multicolumn{1}{c}{ Control } & Prophylaxis & \multicolumn{1}{c}{ Treatment } & P-value \\
\hline ICAM-1 & $3.88 \pm 0.10$ & $7.41 \pm 0.43^{\mathrm{a})}$ & $5.21 \pm 0.18^{\mathrm{b}, \mathrm{c})}$ & $3.24 \pm 0.11^{\mathrm{c})}$ & $<0.001$ \\
MDA & $40.25 \pm 0.27$ & $58.63 \pm 2.41^{\mathrm{a})}$ & $59.25 \pm 3.20^{\mathrm{a})}$ & $57.13 \pm 2.32^{\mathrm{a})}$ & $<0.001$ \\
NOS1/nNOS & $4.71 \pm 0.13$ & $22.15 \pm 0.14^{\mathrm{a})}$ & $14.25 \pm 0.82^{\mathrm{c}, \mathrm{d})}$ & $12.0 \pm 0.14^{\mathrm{c}, \mathrm{d})}$ & $<0.001$ \\
\hline
\end{tabular}

Values are presented as mean \pm standard error of the mean.

Analysis of variance + Tukey-Kramer multiple comparisons test.

ICAM-1, intercellular adhesion molecule 1; MDA, malondialdehyde; NOS1/nNOS, nitric oxide synthase 1/neuronal nitric oxide synthase.

${ }^{\text {a) }} \mathrm{P}<0.001,{ }^{\text {b) }} \mathrm{P}<0.01,{ }^{\text {d) }} \mathrm{P}<0.05$ vs. sham group. ${ }^{\mathrm{c}} \mathrm{P}<0.001$ vs. control group.

\section{Biochemical findings}

The biochemical parameters obtained from blood by ELISA method are introduced in Table 3, and those from pancreatic tissues are in Table 4. As a well-known marker of the severity of AP in blood, CRP and hs-CRP levels were significantly increased in the pancreatitis (control) group compared with the sham group $(\mathrm{P}<0.001)$. Ruscogenin treatment before and after cerulein-induced pancreatitis significantly reduced CRP and hsCRP to normal levels but the reduction in hs-CRP was not as efficient as in CRP levels.

The analysis of ICAM-1 in blood, a cell surface glycoprotein which is typically expressed on endothelial cells and cells of the immune system, showed a significant increase in the pancreatitis (control) and prophylaxis groups compared with the sham group $(\mathrm{P}<0.001)$, while reduced dramatically in the treatment group $(\mathrm{P}<0.001)$. ICAM-1 protein levels in the pancreatic tissues increased considerably in the control and prophylaxis groups compared with the sham group $(\mathrm{P}<0.001$ and $\mathrm{P}<0.01$, respectively), while ruscogenin treatment after pancreatitis induction reduced ICAM-1 levels dramatically, even falling under the levels of sham group $(\mathrm{P}<0.001 \mathrm{vs}$. control group).

Blood IL-6 amounts, one of the inflammatory markers, in the pancreatitis groups were greater than the sham group; the significance was higher in the control group $(\mathrm{P}<0.001)$ than the treatment groups $(\mathrm{P}<0.001)$. Another inflammatory marker, IL-1 $\beta$, was highly elevated in blood of the control group compared to the sham group, with a marked significance $(\mathrm{P}<$ 0.001 ), while the ruscogenin-treated rats had a lowered amount of IL- 6 and IL-1 $\beta$ but failed to decrease to the levels of sham group ( $\mathrm{P}<0.001$ vs. sham group). Pretreatment with ruscogenin was more successful than posttreatment to decrease the serum IL- 6 and IL-1 $\beta$ amounts, but the difference was not significant.

The amount of another inflammatory marker, TNF- $\alpha$, was elevated in blood of the control group and even in the ruscogenin-treated groups with a significant difference compared to the sham group $(\mathrm{P}<0.001)$ though there was still a difference between the control and ruscogenin-treated rats ( $\mathrm{P}<0.001$ vs. control group). However, there was no difference between the prophylaxis and treatment groups.

The amount of one of the pancreatic enzymes, amylase, markedly increased in the pancreatic control group compared with the sham group $(\mathrm{P}<0.001)$. The prophylaxis group showed a significant decrease in amylase levels compared to the control group $(\mathrm{P}<0.001)$ while the decrease in the treatment group was not statistically different compared with the control group. The other enzyme, lipase, increased dramatically in the control and even in the ruscogenin treatment groups $(\mathrm{P}<0.001)$, 
with the difference between control and ruscogenin-treated groups also statistically significant $(P<0.001)$. Ruscogenin successfully reduced the amylase and lipase levels for both preand posttreatment.

Measuring the amount of MDA, one of the toxic stable decomposition products in the pancreatic tissue, the control, prophylaxis, and treatment groups showed significant elevations in comparison to the sham group $(\mathrm{P}<0.001)$. Both pre- or posttreatment with ruscogenin failed to reduce MDA levels in the pancreatic tissues (Table 4).

One of the constitutive NO synthase enzymes, nitric oxide synthase $1 /$ neuronal nitric oxide synthase (NOS1/nNOS), showed a dramatic increase in the tissues of pancreatitis control group, that was more than 5 times the amount measured in the sham group $(\mathrm{P}<0.001)$. Ruscogenin treatment reduced the amount of NOS1/nNOS significantly in the prophylaxis and treatment groups, compared with the control group $(\mathrm{P}<0.001)$. There was no considerable difference between the prophylaxis and treatment group.

\section{Ultrastructural findings}

TEM micrographs of endocrine cells in the sham group showed regular structures of heterochromatic nuclei, evenly distributed rough endoplasmic reticulum (RER), and mitochondria surrounded with normal capillaries (Fig. 4). Exocrine pancreas of the sham group had a number of regular zymogen granules in the cytoplasm, intact mitochondria, euchromatic oval nuclei, and RER in normal ultrastructure. However, the

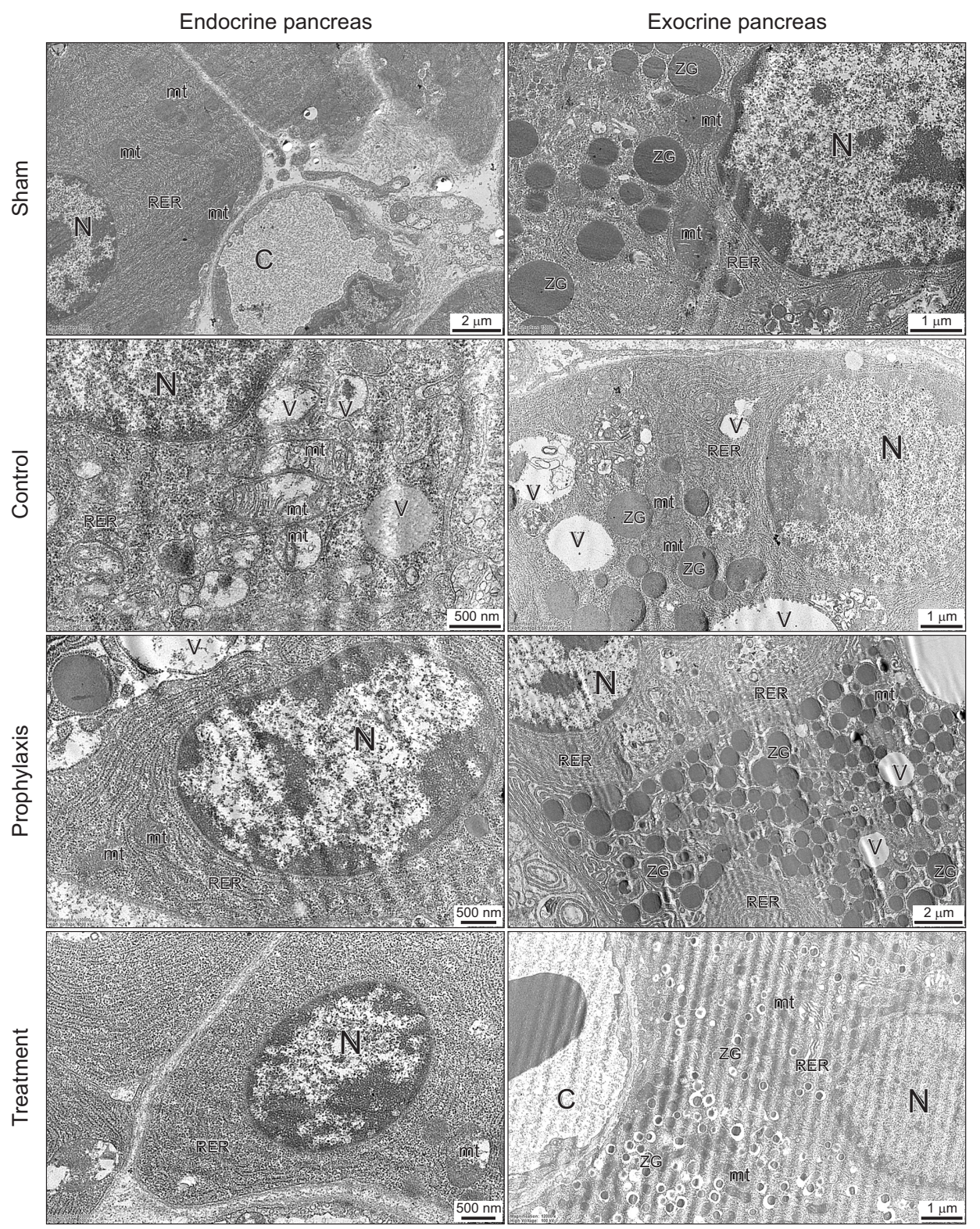

Fig. 4. Ultrastructural micrographs of experimental acute pancreatitis. $\mathrm{N}$ : nucleus, $\mathrm{mt}$ : mitochondria, C: capillary, RER: rough endoplasmic reticulum, ZG: zymogen granules, V: vacuole. Bars: $1 \mu \mathrm{m}$ (for exocrine pancreases of sham, control, and treatment groups); $2 \mu \mathrm{m}$ (for endocrine pancreas of sham and exocrine pancreas of prophylaxis group); $500 \mathrm{~nm}$ (for endocrine pancreases of control, prophylaxis, and treatment groups). 
endocrine cells of AP group had a large number of vacuoles with different ingredients and in varied sizes, as well as disrupted mitochondria with reduced cristae, and degenerated RER with dilated cisterna. The acinar cells of this group had a reduced number of zymogen secretory granules, mitochondria with varied shape of cristae and many vacuoles in the cytoplasm (Fig. 4). The endocrine cells of prophylaxis group had also few vacuoles located in peripheral cytoplasm, but regular intact mitochondria, and evenly distributed RER. The acinar cells of prophylaxis group had also normal and evenly distributed mitochondria and RER, a large number of zymogen granules, as well as a few small vacuoles (Fig. 4). The endocrine cells of treatment group showed regular structures as in the sham group, except a few slightly degenerated mitochondria. The acinar cells of treatment group also had RER with slightly dilated cisternae, a considerable number of smaller zymogen granules with enlarged peripheral spaces, intact normal mitochondria, but no vacuoles (Fig. 4). In brief, the ruscogenin treatment ameliorated the cerulein-induced ultrastructural degenerations in the endocrine and exocrine cells of the pancreatic tissue, especially in the posttreatment group.

\section{DISCUSSION}

This study investigated the protective and therapeutic effects of ruscogenin, a major steroidal sapogenin of Radix Ophiopogon japonicas, in an AP rat model. We demonstrated the molecular mechanism of its protective and therapeutic actions accomplished by improvements in histopathology, by decreasing blood cytokine levels of CRP, hs-CRP levels, TNF- $\alpha$, IL-6, IL-1 $\beta$, ICAM-1, by reducing the pancreatic enzymes amylase and lipase in blood, and by suppressing the expression of NF$\kappa B$, ICAM-1 and NOS1 in pancreatic tissues. The ruscogenin treatment also improved the cerulein-induced ultrastructural degenerations in the endocrine and exocrine cells of the pancreatic tissue, especially in the treatment group.

Many findings of AP in humans are comparable and able to be reproduced in the cerulein-induced AP models, including hyperamylasemia and diverse histopathological findings: infiltration of inflammatory cells within the pancreas, pancreatic edema, acinar cell vacuolization, and the presence of activated pancreatic enzyme within the pancreas. Apart from injury to the acinar cells, ductal and endocrine cells are not damaged [17]. In the present study, we successfully showed the destructive effect of cerulein-induced AP in our model, as elevated amounts of amylase and lipase in blood, and deteriorating histopathology of the pancreas as increased hypertrophy, autophagy, necrosis and vacuolization of acinar cells, and vascular damage, interstitial edema, and ductal variation, as well as the ultrastructure of the endocrine and exocrine cells.

Natural polyphenols have been demonstrated to have several sanative roles in the gastrointestinal organs. Among these roles, antioxidant and anti-inflammatory properties, are the most striking and remarkable ones for the researchers [11]. Moreover, the protective and therapeutic effects of various traditional and supplementary drugs on AP are related to their polyphenol contents [18]. The extracts of the $R$. aculeatus plant have been used in a large number of studies in terms of their pharmacological features. Two main active ingredients of this plant responsible from its pharmacological effects, ruscogenin and neoruscogenin recently gain attention for their antiinflammatory and antioxidant characteristics, as well as their vasoconstrictive and venotonic features. In our previous study, we have also demonstrated that the ruscogenin treatment reduced ulceration in gastric tissues in a chronic ulcer model established by acetic acid induction [19]. The healing effects of ruscogenin in acetic acid-induced gastric ulcer may be due to inhibiting oxidative stress, promoting antioxidant mechanisms and the inhibition of lipid peroxidation by maintaining a balance in collagen content of extracellular cell matrix and ultrastructure [19]. In the present study, we discovered the healing and protective effects of ruscogenin in a cerulein-induced AP rat model by histopathological, immunohistochemical, biochemical, and electron microscopical analysis.

In our previous study, ruscogenin was considered to exert its potent efficacy in gastric ulcer via anti-inflammatory actions through reducing TNF- $\alpha$, IL- 6 and IL- 8 , antioxidant actions through enhancing glutathione activities, in addition to depression in oxidative stress levels and suppressive effects on lipid metabolism [19]. In the present study, the efficient protective and therapeutic effects are probably due to antiinflammatory actions through decreasing blood cytokine levels of CRP, hs-CRP levels, TNF- $\alpha$, IL- 6 , IL-1 $\beta$, ICAM-1, by reducing the pancreatic enzymes amylase and lipase in the blood, and by suppressing the expression of transcription factor NF- $\mathrm{KB}$, and by staving off the augmentation in NO production through suppressing NOS1 in pancreatic tissues.

The pathogenesis of AP is not clear. Recently, studies have focused on trypsinogen activation, pancreatic microcirculation malfunction, calcium overload, and inflammatory and antioxidant pathways [20]. Natural anti-inflammatory agents, such as resveratrol and curcumin, demonstrate a modest preventative role in the treatment of AP $[18,21]$. However, specific and effective therapies and protective mechanisms are lacking. Significant therapeutic effect of resveratrol was noticed in rats with AP by inducing apoptosis of pancreatic acinar cell as a consequence of upregulated FasL gene expression [22]. The mechanism responsible for this protective activity is based on the upregulation of antiapoptotic Bcl-2 and downregulation of proapoptotic Bax and caspase-3 [18]. It seems that resveratrol has a selective bioactivity, being proapoptotic on acinar cells 
and antiapoptotic on other types of cells (e.g., hepatocytes). The resveratrol, with its metabolite (dihydroresveratrol), exerted a dose-dependent anti-inflammatory effect through NF- $\kappa \mathrm{B}$ inhibition and decreased expression of TNF- $\alpha$, IL-1 $\beta$, IL- 6 , and IL- 8 in the pancreas in various animal models of pancreatitis (e.g., cerulein) [23]. Therefore, we investigated the expression of NF- $\mathrm{KB}$ in pancreatic tissue and the cytokine levels (TNF- $\alpha$, IL-1 $\beta$, IL-6) biochemically in our AP model and found that the ruscogenin treatment inhibited their biosynthesis markedly in serum of rats, consistent with the notion that the inhibition of inflammatory cytokines is a therapeutic mechanism against pancreatic damage.

NO is a key signaling molecule in the pathogenesis of inflammation, but its role in AP has not been enlightened clearly yet [24]. There are contradictory findings concerning the effects of polyphenols on the production of NO and NOS. For example, resveratrol was considered to activate endothelial NOS which was found to be protective against cerulein-induced AP in mice, while inducible NOS exhibited proinflammatory effects in the same animal model [25]. Therapeutic blockade of inducible NOS (iNOS) or nNOS provides benefits in terms of inhibition of the acute pancreatitis-related abdominal hyperalgesia, while iNOS inhibition also ameliorates inflammatory cell influx to the pancreas and reduces the resultant hyperamylasemia and NOx levels, thus representing alternative pharmacological strategies for treatment of clinical severe pancreatitis. nNOS staining was reported (without NADPH-d analysis) in rat acini with agonistevoked $\left[\mathrm{Ca}^{2+}\right]$ oscillations [26], but nNOS has not been shown in cerulein-induced AP in rats before. In the present study, NOS1/nNOS showed a dramatic increase in the tissues of AP rats, while ruscogenin pre- and posttreatment reduced the amount of NOS1/nNOS significantly, showing a protective and therapeutic effects of ruscogenin via altering NO pathways.

As a limitation in the present study, we did not examine the expressions of other 2 isoforms of NOS, namely endothelial NOS (eNOS) and iNOS. eNOS is the main isoform influencing the initiation of cerulein-induced AP and eNOS-derived NO exerts a protective effect through actions on nonacinar cell types, most likely endothelial cells [27]. However, all aspects of the biochemical analysis for nNOS reveals the effectiveness of ruscogenin in AP through inhibiting nNOS production and thus, the valuable information added to the literature by this study is incontrovertible.

Polyphenols have been implicated to induce pancreatic superoxide dismutase (SOD) and inhibit the production of MDA, a marker of lipid peroxidation, within the first 6 hours of AP induction in rats [22]. In our study, we were able to show an inductive effect of cerulein to increase lipid peroxidation in pancreatic tissues, indicated by increasing MDA levels. However, ruscogenin failed to decrease this effect, probably due to long-term treatment. However, a study investigating the chemopreventive potential of Tribulus terrestris, a tropical plant which contains ruscogenin, in rats with skin carcinogenesis, found that treatment of the extract increase reduced glutathione levels and decrease MDA formation. The decreased lipid peroxidation in the liver homogenate of Tribulus treated animals is correlated well with the induction of antioxidant enzymes above basal level [28]. A single-blind, randomized, placebo-controlled study evaluated the effects of oral mixture of curcumin with piperine $(5 \mathrm{mg})$ in tropical pancreatitis, a type of chronic pancreatitis. The herbal formulation significantly reduced the erythrocyte MDA level [29]. On the contrary, preor posttreatment with ruscogenin failed to reduce MDA levels in the pancreatic tissues. Since lipid peroxidation has been implicated in the pancreatitis, it is assumed that antioxidant components of the plant extracts could act as potential drugs to prevent or cure the disease $[22,23]$. To verify this hypothesis, in future, SOD, myeloperoxidase, or glutathione amounts in pancreatic tissues and blood of rats should be investigated to show the exact antioxidant effects of ruscogenin in AP.

Ruscogenin has been found to have valuable anti-inflammatory and antithrombotic activities in inflammatory diseases. A dose-dependent anti-inflammatory effect of the crude steroidal saponin from the rhizomes of Ruscus aculeatus L. (Ruscaceae) was shown in 2 rat models of acute inflammation [13]. Another study suggested that ruscogenin considerably inhibited adhesion of leukocytes to a human umbilical vein endothelial cell line (ECV304) injured by TNF-alpha in a dose-dependent manner [30]. Huang et al. [13] reported that ruscogenin dramatically suppressed zymosan A-evoked peritoneal total leukocyte migration in mice in a dosedependent manner, and also inhibited TNF- $\alpha$-induced over expression of ICAM-1 both at the mRNA and protein levels and considerably suppressed NF- $\mathrm{B}$ activation. Cao et al. [27] reported the protective effect of ruscogenin after ischemic stroke, by inhibiting IL-1 $\beta$ and Caspase-1, thus decreasing inflammation in vivo and in vitro. Since the main cause of AP is acute inflammation, we expected and observed an inhibitory effect of ruscogenin on NF- $\kappa B$ and ICAM-1 in cerulein-induced pancreatic tissues, and serum TNF- $\alpha$, IL- 6 and IL- $1 \beta$, ICAM-1 levels, suggesting a possible molecular mechanism of ruscogenin to be anti-inflammatory effect through NF- $\mathrm{kB}$, ICAM-1, TNF- $\alpha$, IL- 6 and IL-1 $\beta$.

Accumulating evidence has demonstrated that traditional Chinese medicine reduces the levels of serum and urinary amylase, decreases the permeability of capillaries, depresses the production of inflammatory cytokines, inhibits neutrophilic granulocyte activation, and attenuates pancreatic injuries. These benefits block multiple steps in the development of AP according to experimental and clinical studies. Based on its characteristics of improved symptoms, reduced medical costs, and increased satisfaction of acute pancreatic patients, 
these medical agents appear to be a promising complementary and alternative therapy for the treatment of disease [29,30]. In the present study, pre- and posttreatment by ruscogenin successfully attenuated pancreatic injury by reducing levels of the pancreatic enzymes amylase and lipase in the ceruleininduced AP rat model, as reflected by improved histopathologic scores.

In our previous study, we showed acetic acid-induced gastritis resulting in devastating damage on ultrastructure of chief and parietal cells while ruscogenin almost completely ameliorated these effects and preserved the ultrastructure, suggesting a correlation between cellular integrity and anti-inflammatory effects [19]. In this study, the ruscogenin treatment ameliorated the cerulein-induced ultrastructural degenerations in the endocrine and exocrine cells of pancreatic tissue, especially in the treatment group.

In conclusion, the present findings have demonstrated that the beneficial protective and therapeutic effects of ruscogenin appears to be mediated by diminished expression of $\mathrm{NF}_{-\mathrm{K}} \mathrm{B}$ and ICAM-1 in the pancreatic tissue, and by reducing serum
TNF- $\alpha$, IL- 6 and IL-1 $\beta$, CRP, hs-CRP, amylase, lipase, and ICAM1. Evidently, this nominates ruscogenin as a highly promising supplementary agent to be considered in the treatment of AP, and even as a protective agent against damages induced by disease.

\section{CONFLICTS OF INTEREST}

No potential conflict of interest relevant to this article was reported.

\section{ACKNOWLEDGEMENTS}

The present project was supported by Research and Development Expenses Account under Circulating Capital Budget of University of Health Science Bagcilar Training and Research Hospital (Project No: 2016/24). Authors thank to Assoc. Prof. Ilknur Dag from Central Research Laboratory Application and Research Center of Eskisehir Osmangazi University, Turkey, for the analysis by transmission electron microscopy.

\section{REFERENCES}

1. Kim H. Cerulein pancreatitis: oxidative stress, inflammation, and apoptosis. Gut Liver 2008;2:74-80.

2. Fisic E, Poropat G, Bilic-Zulle L, Licul V, Milic S, Stimac D. role of IL-6, 8, and 10, sTNFr, CRP, and pancreatic elastase in the prediction of systemic complications in patients with acute pancreatitis. Gastroenterol Res Pract 2013;2013:282645.

3. McKay CJ, Gallagher G, Brooks B, Imrie $\mathrm{CW}$, Baxter JN. Increased monocyte cytokine production in association with systemic complications in acute pancreatitis. Br J Surg 1996;83:919-23.

4. Al-Bahrani AZ, Ammori BJ. Clinical laboratory assessment of acute pancreatitis. Clin Chim Acta 2005;362:26-48.

5. Schoenberg MH, Buchler M, Gaspar M, Stinner A, Younes M, Melzner I, et al. Oxygen free radicals in acute pancreatitis of the rat. Gut 1990;31:1138-43.

6. Yu JH, Lim JW, Namkung W, Kim H, Kim KH. Suppression of cerulein-induced cytokine expression by antioxidants in pancreatic acinar cells. Lab Invest 2002;82:
1359-68

7. Gorelick FS, Adler G, Kerin HF. Ceruleininduced pancreatitis. In: Go VW, DiMagno EP, Gardner JD, Lebenthal E, Reber HA, Scheele GA, editors. The pancreas: biology, pathobiology, and disease. 2nd ed. New York: Raven Press; 1993. p. 501-26.

8. Lerch MM, Adler G. Experimental animal models of acute pancreatitis. Int J Pancreatol 1994:15:159-70.

9. Zerem E, Imamovic G, Susic A, Haracic B. Step-up approach to infected necrotising pancreatitis: a 20-year experience of percutaneous drainage in a single centre. Dig Liver Dis 2011;43:478-83.

10. Kambhampati S, Park W, Habtezion A. Pharmacologic therapy for acute pancreatitis. World J Gastroenterol 2014;20:1686880.

11. Sugiyama Y, Kato S, Abe M, Mitsufuji S, Takeuchi K. Different effects of dexamethasone and the nitric oxide synthase inhibitor L-NAME on caerulein-induced rat acute pancreatitis, depending on the severity. Inflammopharmacology 2005;13:
291-301.

12. Ogino K, Hobara T, Ishiyama H, Yamasaki K, Kobayashi H, Izumi Y, et al. Antiulcer mechanism of action of rebamipide, a novel antiulcer compound, on diethyldithiocarbamate-induced antral gastric ulcers in rats. Eur J Pharmacol 1992;212:913.

13. Huang YL, Kou JP, Ma L, Song JX, Yu BY. Possible mechanism of the anti-inflammatory activity of ruscogenin: role of intercellular adhesion molecule-1 and nuclear factor-kappaB. J Pharmacol Sci 2008; 108:198-205.

14. Rouse R, Xu L, Stewart S, Zhang J. High fat diet and GLP-1 drugs induce pancreatic injury in mice. Toxicol Appl Pharmacol 2014;276:104-14.

15. Erturkuner SP, Yaprak Sarac E, Gocmez SS, Ekmekci H, Ozturk ZB, Seckin I, et al. Anti-inflammatory and ultrastructural effects of Turkish propolis in a rat model of endotoxin-induced uveitis. Folia Histochem Cytobiol 2016;54:49-57.

16. Seckin I, Uzunalan M, Ayaz Pekpak M, 
Kokturk S, Sonmez HA, Gungor ZB, et al. TGF-b1 expression and mesangial alterations in rat glomeruli of an experimental chronic nephrosis model. Cerrahpaşa Tip Dergisi 2019;43:6-12.

17. Hyun JJ, Lee HS. Experimental models of pancreatitis. Clin Endosc 2014;47:212-6.

18. Jha RK, Ma Q, Lei Z, Sha H. Resveratrol ameliorates the deleterious effect of severe acute pancreatitis. Cell Biochem Biophys 2012;62:397-402.

19. Ercan G, Ilbar Tartar R, Solmaz A, Gulcicek OB, Karagulle OO, Meric S, et al. Potent therapeutic effects of ruscogenin on gastric ulcer established by acetic acid. Asian J Surg 2019 Jul 22 [Epub]. pii: S10159584(19)30365-3. https://doi.org/10.1016/j. asjsur.2019.07.001.

20. Dawra R, Sah RP, Dudeja V, Rishi L, Talukdar R, Garg P, et al. Intra-acinar trypsinogen activation mediates early stages of pancreatic injury but not inflammation in mice with acute pancreatitis. Gastroenterology 2011;141:2210-7.e2.

21. Gukovsky I, Reyes CN, Vaquero EC, Gukovskaya AS, Pandol SJ. Curcumin ameliorates ethanol and nonethanol ex- perimental pancreatitis. Am J Physiol Gastrointest Liver Physiol 2003;284:G85-95.

22. Li ZD, Ma QY, Luo YH. Effect of resveratrol-induced FasL up-regulation on the apoptosis of pancreatic acinar cells in rats with severe acute pancreatitis. Nan Fang Yi Ke Da Xue Xue Bao 2009:29:454-7.

23. Lin ZS, Ku CF, Guan YF, Xiao HT, Shi XK, Wang HQ, et al. Dihydro-resveratrol ameliorates lung injury in rats with cerulein-induced acute pancreatitis. Phytother Res 2016:30:663-70.

24. Camargo EA, Santana DG, Silva CI, Teixeira SA, Toyama MH, Cotrim C, et al. Inhibition of inducible nitric oxide synthasederived nitric oxide as a therapeutical target for acute pancreatitis induced by secretory phospholipase A2. Eur J Pain 2014;18:691-700.

25. Gulcubuk A, Haktanir D, Cakiris A, Ustek D, Guzel O, Erturk M, et al. The effects of resveratrol on tissue injury, oxidative damage, and pro-inflammatory cytokines in an experimental model of acute pancreatitis. J Physiol Biochem 2014:70: 397-406.

26. Xu X, Zeng W, Diaz J, Lau KS, Gukovskaya
AC, Brown RJ, et al, nNOS and Ca2+ influx in rat pancreatic acinar and submandibular salivary gland cells. Cell Calcium 1997:22:217-28.

27. Cao G, Jiang N, Hu Y, Zhang Y, Wang G, Yin $\mathrm{M}$, et al. Ruscogenin attenuates cerebral ischemia-induced blood-brain barrier dysfunction by suppressing TXNIP/ NLRP3 inflammasome activation and the MAPK pathway. Int J Mol Sci 2016 Aug 29; 17(9). pii: E1418. https://doi.org/10.3390/ ijms17091418.

28. Kumar M, Soni AK, Shukla S, Kumar A. Chemopreventive potential of Tribulus terrestris against 7,12- dimethylbenz (a) anthracene induced skin papillomagenesis in mice. Asian Pac J Cancer Prev 2006; 7:289-94.

29. Durgaprasad S, Pai CG, Vasanthkumar, Alvres JF, Namitha S. A pilot study of the antioxidant effect of curcumin in tropical pancreatitis. Indian J Med Res 2005;122: 315-8.

30. Ma L, Kou JP, Huang Y, Yu BY. Effect of ruscogenin in on adhesion of HL-60 cells to ECV304 cells. Chin Pharmacol Bull 2006;22:706-9. 